\title{
A Constructive Algorithm for Transforming Conics in a Circle on Imaginary Laguerre Points
}

\author{
Elena Boyashova ${ }^{1}$, Denis Voloshinov ${ }^{1}$ and Tatyana Musaeva ${ }^{1}$ \\ ${ }^{1}$ St. Petersburg State University of Telecommunication, Bol'shevikov, 22/1, Saint-Petersburg, 193232, Russia
}

\begin{abstract}
The article is devoted to the consideration of the properties of Laguerre points in their constructive relationship with the solution of the problem of transforming a pair of conical curves into two circles. Geometric schemes are presented that reveal the principle of specifying a collinear transformation that establishes a correspondence between conics and their images in the form of circles, including if the Laguerre points defining this transformation are imaginary. In the solution of the problem, a geometric scheme for the formation of the main conjugations of conics is given, one of which is a circle. The conclusion is substantiated that the radical axis of the bundle of circles is a circle that has split into a pair of straight lines, one of which is infinitely distant. An algorithm for the formation of a series of elliptic curves induced by Laguerre points is presented.
\end{abstract}

\section{Keywords}

Laguerre points, involution of point series, collineation, conjugation of conical curves

\section{Introduction}

The development and improvement of modern information technologies in the field of geometric modeling has provided constructive geometry with new opportunities both in the field of supporting information-intensive scientific research and in the application of its methods for solving practical problems $[4,8,9]$. It became possible to create and implement in drawings models of images and transformations $[1,15,16]$ not only two-dimensional and three-dimensional, but also multidimensional spaces, as well as to implement such models in the form of automatically synthesized programs executed on various computing devices $[4,16,24]$. The emerging opportunities aroused interest in new studies of seemingly well-studied mathematical images: conics, quadrics and related images of multidimensional spaces $[3,5-7,20]$. The solution of problems operating with such images becomes extremely difficult without taking into account the presence of imaginary images in them; it requires research related to the search for new yet unknown regularities, understanding their geometrical nature and formulating generalizations, developing new determinants of the investigated images and their attendant transformations. This paper presents some results of research of such kind on the example of identifying the relationship of Laguerre points with quadratic images of a plane.

A collinear transformation defined in a plane associates the linear preimages incident with this plane with the corresponding linear images, and maps second-order curves to second-order curves [13, 25]. Since in affine geometry the circle is a particular form of a curve of the second order, and in projective geometry it does not differ among curves of the second order in general, then it, naturally, is transformed by any non-identical collineation into some conical section. Collinear transformations form a group; therefore, there is also an inverse transformation that takes an arbitrary non-degenerate conic to a circle.

The method for determining the frame of such a collineation is to select a homology (a particular form of a collinear transformation) in which two points of the preimage and the image, respectively, coincided, and the remaining two points of the second-order curve would translate a pair of cyclic points of the plane at which all circles of the plane have common crossection. Cyclic points by their nature are

GraphiCon 2021: 31st International Conference on Computer Graphics and Vision, September 27-30, 2021, Nizhny Novgorod, Russia EMAIL: helen.glass@mail.ru (E. Boyashova); denis.voloshinov@yandex.ru (D. Voloshinov); neli_6868@mail.ru (T. Musaeva) ORCID: 0000-0002-6539-5336 (E. Boyashova); 0000-0001-5248-4359 (D. Voloshinov); 0000-0003-0717-0507 (T. Musaeva)

(c) (i) 2021 Copyright for this paper by its authors.

Use permitted under Creative Commons License Attribution 4.0 International (CC BY 4.0).

CEUR Workshop Proceedings (CEUR-WS.org) 
imaginary $[10-12,14,17,19,21,23]$ and they are incident to the line of infinity. Algorithms for performing such a transformation are well known [18, 22], and, based on the incidence with the line at infinity, they do not require reference to the imaginary values of cyclic points.

A natural continuation of this problem is a search for transformation of two arbitrary non-degenerate conics into two circles by means of a collinear conversion. The presence of such an algorithm makes it possible, for example, to solve the problem of smooth conjugation of two conics by the third conic. In $[18,22]$, it was shown how the search for the frame of such a collinear transformation is carried out. A distinctive feature of this algorithm is the use of Laguerre points $[2,13,25]$ originating from equal involutions induced by both conics on some straight line.

However, despite the legitimacy and general correctness of this approach to solving the problem, in its practical solution, certain instrumental difficulties may arise due to the fact that Laguerre points may turn out to be imaginary, and it becomes difficult to perform a collinear transformation by conventional means.

This article is devoted to the consideration of a set of algorithms and related issues of constructive geometry, which make it possible to overcome the difficulties of performing a collinear transformation that depends on the complex values of Laguerre points.

\section{Conic conjugation algorithms}

Let two ellipses $a$ and $b$ having no real points of intersection be given on the plane (Fig. 1).
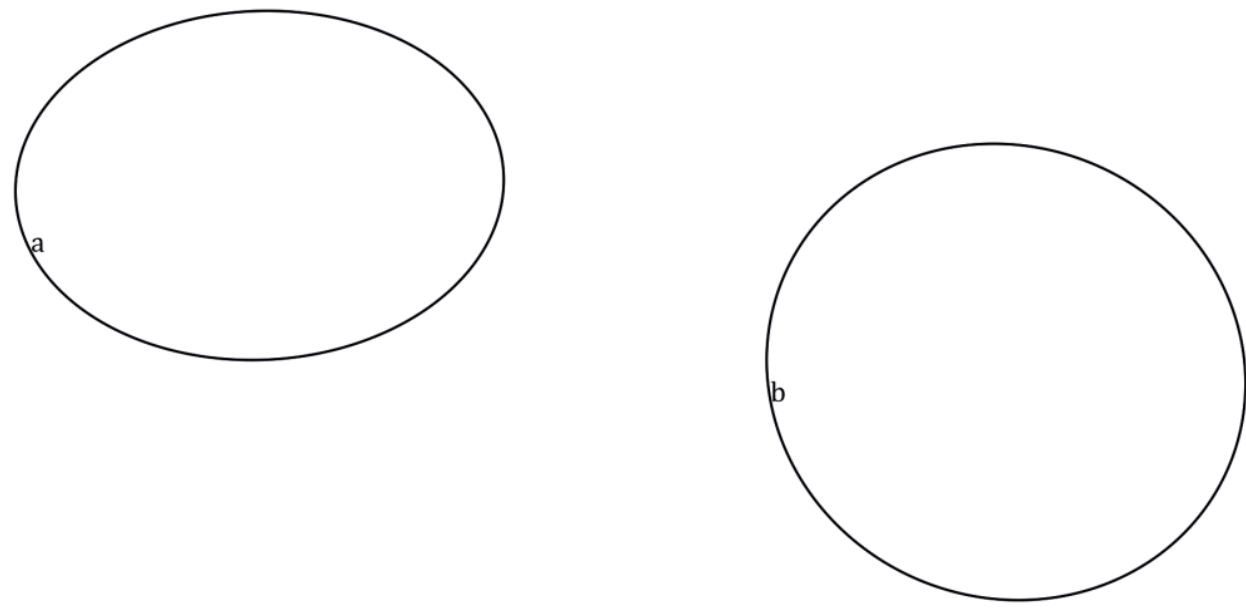

Figure 1: Two original conics

Let's perform the polar conic $a$ transformation with respect to the conic $b: a^{\prime}=\xi_{b}(a)$ and the conic $b$ transformation with respect to the conic $a: b^{\prime}=\xi_{a}(b)$. Let's find the intersection points of the conics $K_{1}, K_{2}, K_{3}, K_{4}=b \times a^{\prime}$ and $L_{1}, L_{2}, L_{3}, L_{4}=a \times b^{\prime}$. The points of intersection of the diagonals of a hexagon, built on four points $K_{1}, K_{2}, K_{3}, K_{4}$, allow to define an auto-polar triangle with vertices $P, Q$ и $R$ relative to the conic $b$. It is easy to show that the diagonals of a hexagon, built on four points $L_{1}, L_{2}, L_{3}, L_{4}$, form an auto-polar triangle with the same vertices, i.e. coinciding with the one already built. Thus, the triangle $\triangle P Q R$ is a common auto-polar triangle for both original conics $a$ and $b$.

Let us find the intersection points of the straight line $Q R$ with the original conics $a$ and $b$ : $A_{1}, A_{2}=Q R \times a, B_{1}, B_{2}=Q R \times b$ as well as the images of the infinitely distant straight line $i^{\infty}$ in the polarities $\xi_{a}$ and $\xi_{b}: C_{a}=\xi_{a}\left(i^{\infty}\right)$ and $C_{b}=\xi_{b}\left(i^{\infty}\right)$. Draw a straight line $p \times Q R=Z^{\infty}$ passing the point $P ; p \sim P$. Considering the pair $p-P$ as a common tangent to the conics $a^{\prime \prime}$ and $b^{\prime \prime}$, let's construct these conics by making the connection $a^{\prime \prime}=A_{1} \circ A_{2} \circ C_{a} \circ P \circ p$ and $b^{\prime \prime}=B_{1} \circ B_{2} \circ C_{b} \circ P \circ p$. By construction, these conics at the intersection have a common double point $P$, and also form two more separate points $U, V=a^{\prime \prime} \times b^{\prime \prime}$. Straight lines $P U=u$ and $P V=v$ are those lines on which the original 
conics $a$ and $b$ induce the corresponding equal involutions $\left.\eta_{u}\right|_{u} ^{a}=\left.\eta_{u}\right|_{u} ^{b}$ and $\left.\eta_{v}\right|_{v} ^{a}=\left.\eta_{v}\right|_{v} ^{b}$. In fact, these lines pass through the corresponding complex conjugate points formed by the intersection of the original conics $a$ and $b$.

Choosing any of the obtained lines, $u$, for example, we define on it an involution from any of the original conics. Conic $a$ induces an involution $\left.\eta_{u}\right|_{u} ^{a}$. The involution of a point series on a straight line that does not have real intersection points with the conic inducing involution, forms two real Laguerre points $G_{1}$ and $G_{2}$, from which each pair of corresponding points of the series is visible at right angles. Taking as the center of homology one of the Laguerre points, say $G_{1}$, and two arbitrary non-coinciding points $S \neq T, S \sim u T \sim u$, draw lines $s=G_{1} \circ S$ and $t=G_{1} \circ T$ and define the corresponding infinitely distant points $S^{\infty}$ and $T^{\infty}$ on them. As the axis of homology, we choose an arbitrary line $x \| u$ and project points $S$ and $T$ onto it from the center $G_{1}$ to obtain the corresponding points $S^{*}$ and $T^{*}$. Then collineation $\left.\chi\right|_{S^{\infty}, S^{*}, T^{\infty}, T^{*}}$ will provide the transformation $a^{*}=\chi(a)$ and $b^{*}=\chi(b)$, where $a^{*}$ and $b^{*}$ are the essence of the circle (Fig. 2).

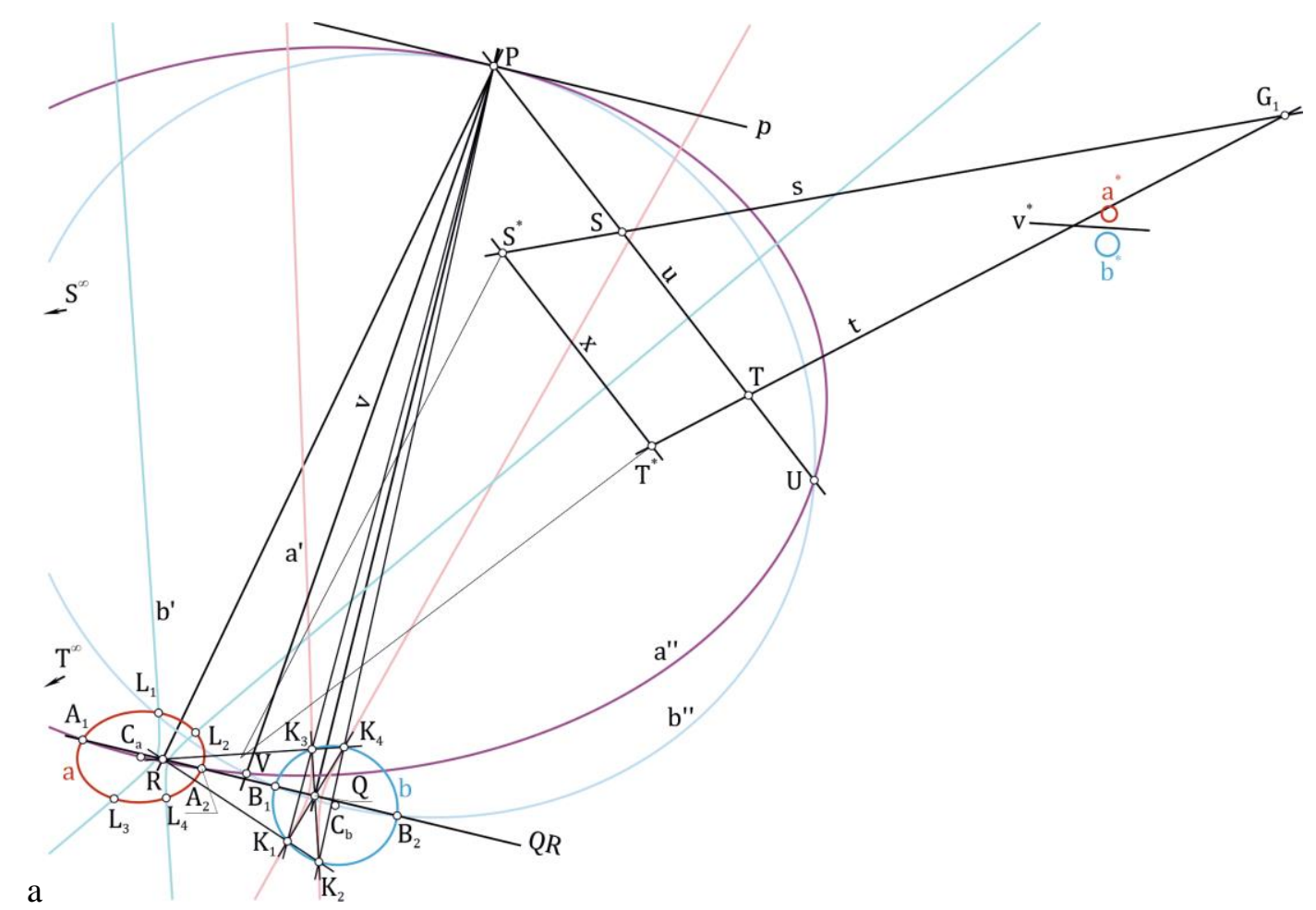

Figure 2: Converting two conics to two circles based on real Laguerre points

As it can be seen from the presented example, when executing the algorithm, there was no need to explicitly refer to objects with complex-valued values, which means that all constructions can be performed using traditional tools on sets of real values of objects. Drawing conjugate circles to circles $a^{*}$ and $b^{*}$ transforming the result in reverse collineation $\chi^{-1}$ provides control over the process of constructing conic conjugates of the two original conics $a$ and $b$.

Let us now consider the same algorithm, but with different initial data. Let the initial curves $a$ and $b$ are two hyperbolas located on the plane as shown in Fig. 3. 

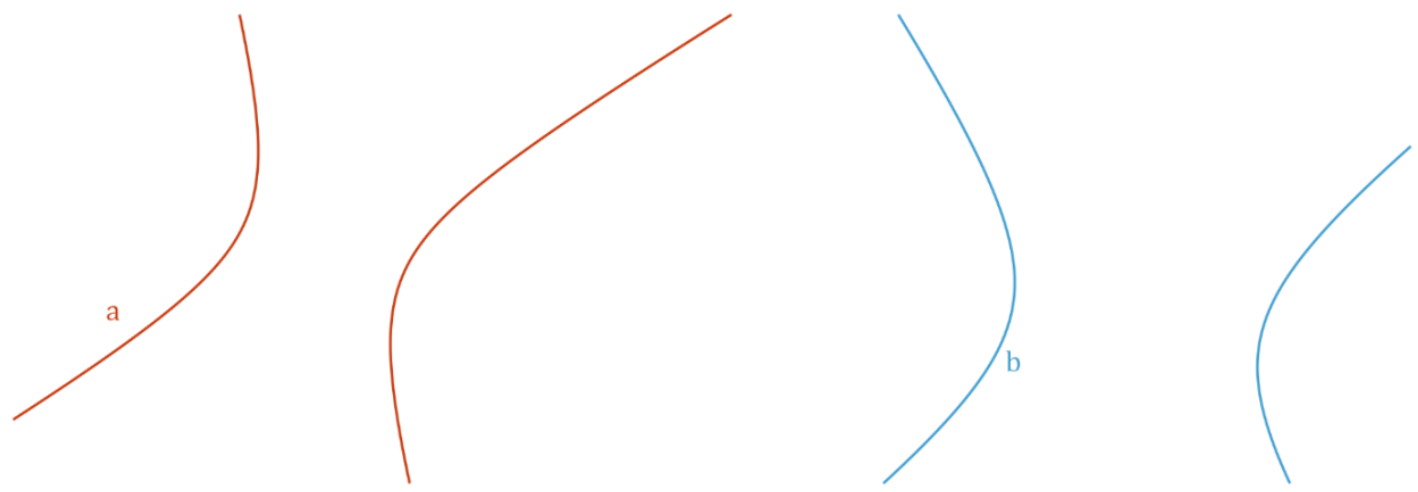

Figure 3: Initial hyperbolas in the problem of conjugation of conics

Performing the same operations as in the previous case, we will come to the conclusion that the Laguerre points $G_{1}$ and $G_{2}$ will turn out to be complex-valued, which means that it becomes impossible to perform the collinear transformation $\chi$ with conventional tools (Fig. 4).

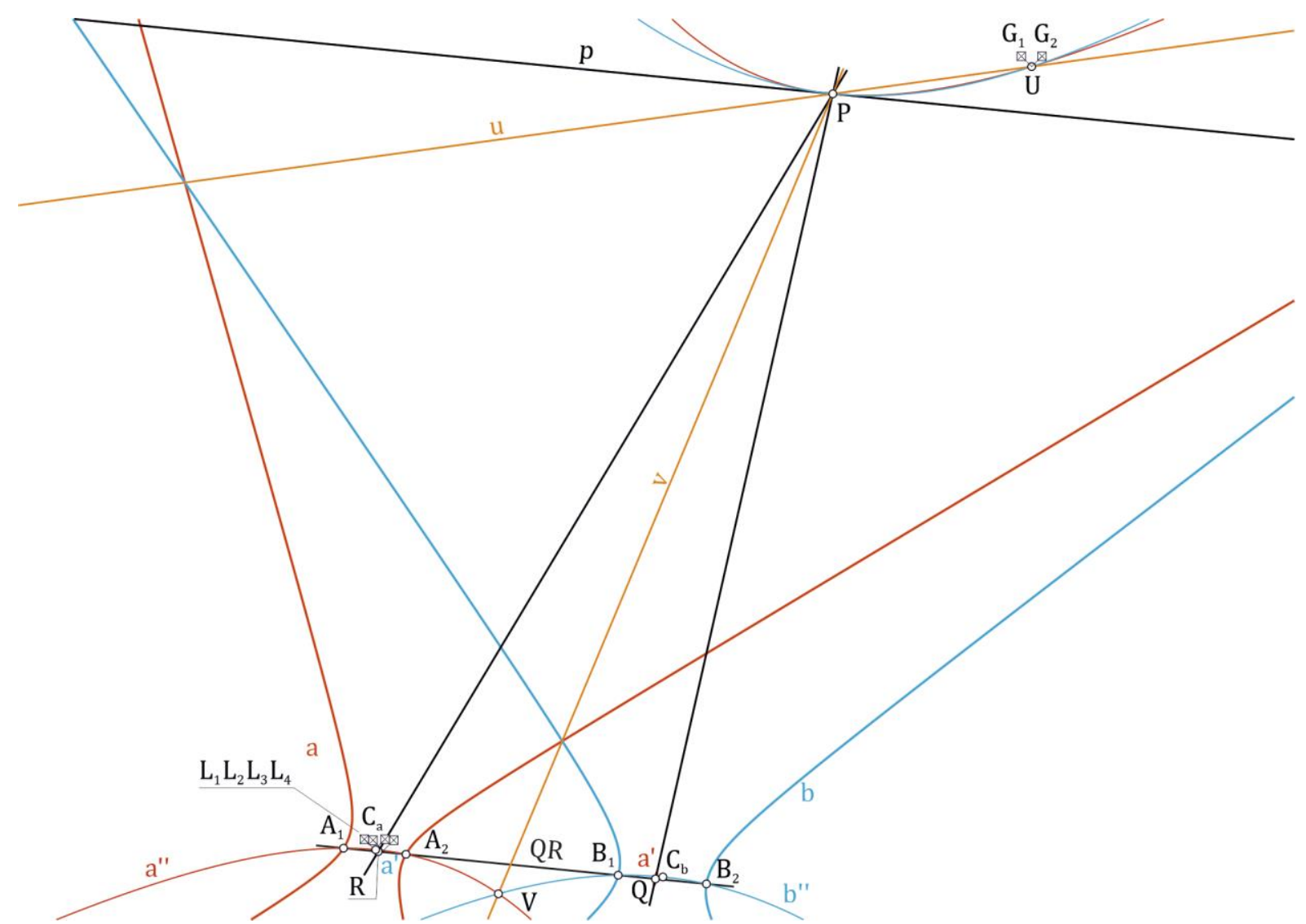

Figure 4: An example of the formation of imaginary Laguerre points

To solve this problem, consider an auxiliary problem. Let there be some conic $m$ and a straight line $n$ that has real-valued points $N_{1}$ and $N_{2}$ at the intersection with the conic. This means that the involution $\left.\eta_{n}\right|_{n} ^{m}$ is of hyperbolic type and its Laguerre points are imaginary. Let us find the required collineation $\chi$ by performing a number of indirect additional actions.

Consider the following construction. Let's draw a circle passing through antipodal points $N_{1}$ and $N_{2}$. Note that the radius of this circle is equal in absolute value to the radius of the imaginary circle, which could be drawn on imaginary antipodal points $G_{1}$ and $G_{2}$. Draw the perpendicular $h \perp n, h \sim C_{d}$ 
from the center $C_{d} \sim n$ of the circle $d$. A straight line $h$ intersecting a circle $d$ forms real points $J_{1}, J_{2}=h \times d$. By analogy with the previous algorithm, we construct a collineation $\delta$ according to the following scheme: draw a straight line $y \| n$, mark two arbitrary points $E \sim n$ and $F \sim n$ on a straight line $n$, and project them from the center $J_{1}$ onto a straight line $y$ to obtain points $E^{*} \sim y$ and $F^{*} \sim y$ . Using straight lines $e=J_{1} \circ E$ and $f=J_{1} \circ F$, let's define the infinitely distant points $E^{\infty}$ and $F^{\infty}$ and determine the collineation $\delta \mid \begin{gathered}E, E^{*}, F, F^{*} \\ E^{\infty}, E^{*}, F^{\infty}, F^{*}\end{gathered}$

Having now performed the collinear transformation of the conic $m$, we obtain a conic $m^{*}=\delta(m)$ that is not a circle, but an equilateral hyperbola. Therefore, a conic $m^{*}$ has two principal conjugate conics, one of them is a circle. By denoting the collineation $\varepsilon$ that transforms the hyperbola into a circle, we obtain the formula for the required collineation $\chi=\delta \cdot \varepsilon ; m^{* *}=\chi(m)$. Thus, the appearance of complex-valued Laguerre points in the construction is not an obstacle to solving the problem, and it can be performed without referring to imaginary images (Fig. 5).

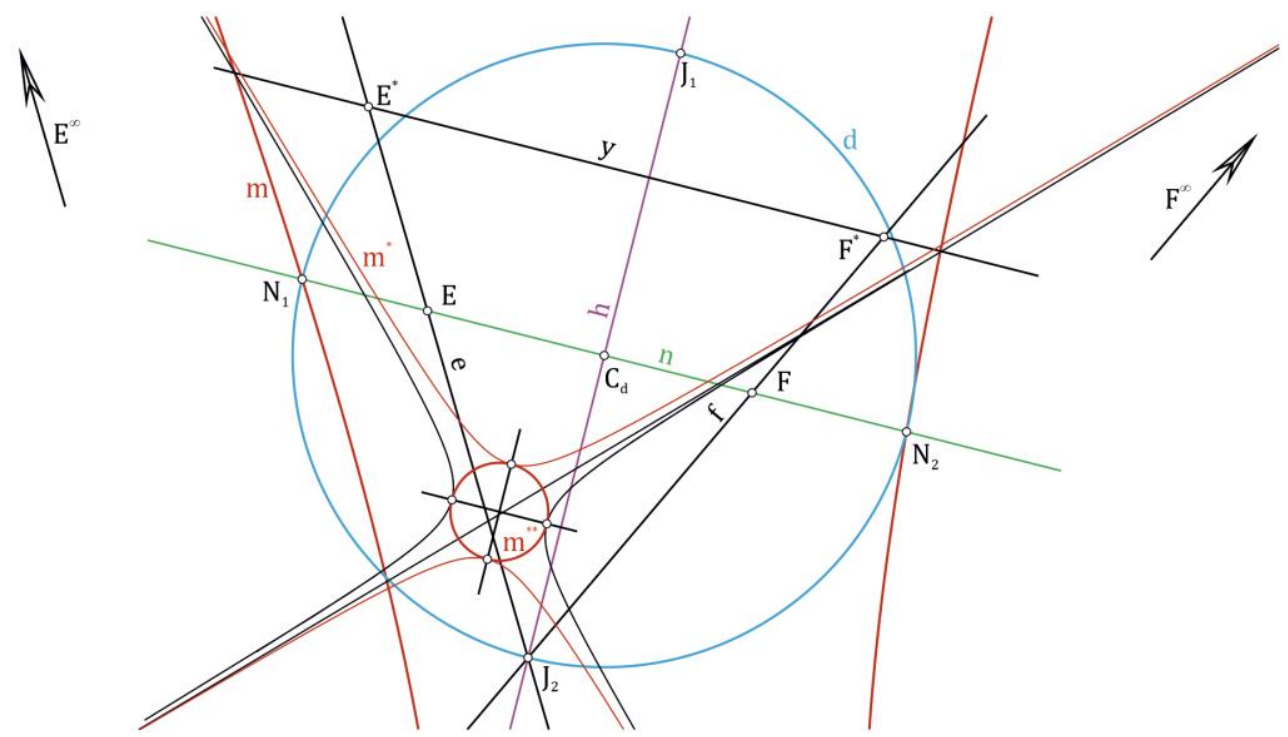

Figure 5: Formation of two conjugate cones, one of which is a circle

Let's get back to the main task. Keeping the notation used in the additional construction, we complete its solution. The result is shown in Fig. 6. As in the previous example, the controlled construction of circles to circles $a^{*}$ and $b^{*}$ with the subsequent transformation of the result in reverse collineation $\chi^{-1}$ allows us to perform conjugation of hyperbolic curves.

Let's perform a collinear transformation $\chi$ with respect to lines $u$ and $v: u^{*}=\chi(u), v^{*}=\chi(v)$. It is easy to find that one of these straight lines $\left(v^{*}\right)$ is the radical axis of the resulting circles, and the second one becomes the infinitely distant straight line $v^{*}$. This construction confirms once again that the radical axis of a bundle of circles cannot be considered in isolation from the infinitely distant straight line. In essence, both of these straight lines are items of a degenerate radical circle that split into two linear parts, and the addition of the radical axis with a second component, an infinitely distant straight line, eliminates the problem of intersecting a bundle of circles with a straight line from exception. The proposed extension of the concept of the radical axis provides a single constructive commonality of its elements, as a result of which, without any restrictions, it can be assumed that any component of such bundle has two points of intersection with a straight line. 


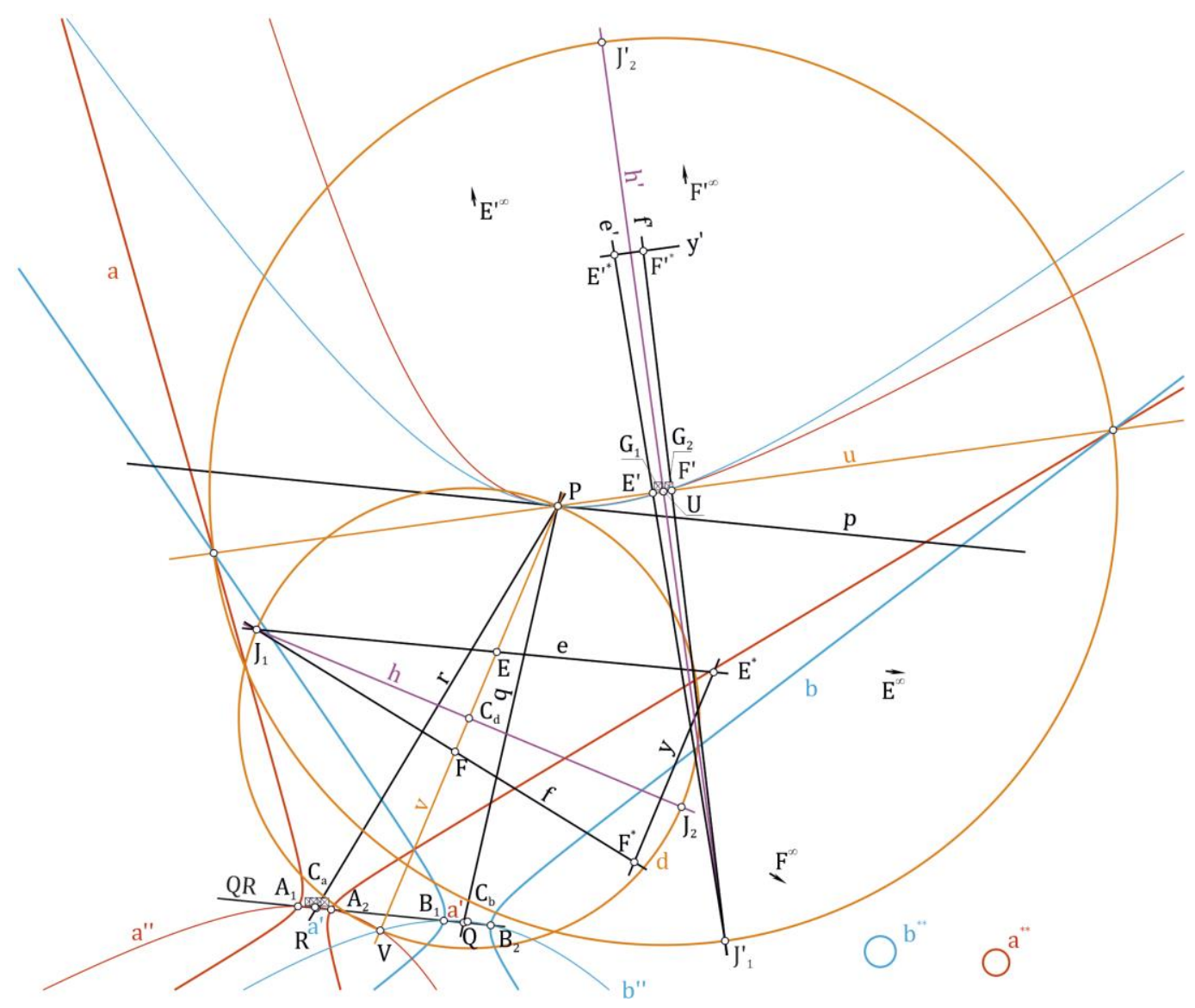

Figure 6: Performing conic transforms using imaginary Laguerre points

\section{Laguerre points and geometric images induced by them}

It has already been noted that the complex-valued Laguerre points produced by involution $\left.\eta_{u}\right|_{u} ^{a}$ and considered as antipodal define an imaginary circle $d$ with a radius equal in magnitude to the radius of the circle defined at the antipodal points $N_{1}$ and $N_{2}$ (Fig. 5). The four focal points of the ellipse have a similar property (two focuses are real, and the remaining two are complex conjugate). Thus, a number of elliptic curves are associated with Laguerre points, the method of constructing representatives of which is shown in Fig. 7.

Let there be given four focal points $\left(F_{1}, F_{2}\right)$ and $\left(\bar{F}_{3}, \bar{F}_{4}\right)$, satisfying the above conditions. Let's choose some control point $A$ and draw a circle $w=A \circ \bar{F}_{3} \circ \bar{F}_{4}$. Let's find the center of the circle $w$ and draw a straight line through it: $m \| \bar{F}_{3} \bar{F}_{4}, m \sim C_{d}$. Let's define the points $M_{1}, M_{2}=w \times m$. Let's construct a circle $z=M_{1} \circ F_{1} \circ F_{2}$ and find its center $C_{z}$. The point $O$ that is the center of the circle $d=F_{1} \circ F_{2}$ and considered as the center of the desired ellipse $e$, as well as the points $C_{d}$ and $C_{z}$ allows you to build an ellipse $e\left(O, C_{d}, C_{z}\right)$ controlled by the point $A$. Thus, we have obtained a one-parameter series of confocal conics induced by Laguerre points in the problem under consideration (Fig. 8). Note also that the focal circle $d$ and its conjugate paired imaginary circle $\bar{d}=\bar{F}_{3} \circ \bar{F}_{4}$ are the inversion circles for circles $t_{1}$ and $t_{2}$ with centers at a point $O$ and are conjugate to the circles $w$ and $z$, defining a system of confocal conics and form two conjugate salinons $t_{1}-w-t_{2}$ and $t_{1}-z-t_{2}$.

A feature of this series is the tendency of the shape of ellipses to the shape of a circle with an increase in the size of their semiaxes. It can be seen from the drawing that the set of points $\left\{M_{1}\right\}$ defines an 
isosceles hyperbola $g$ conjugate to a circle $d$, which implies the existence in this system of one more isosceles hyperbola, also conjugate to these curves.

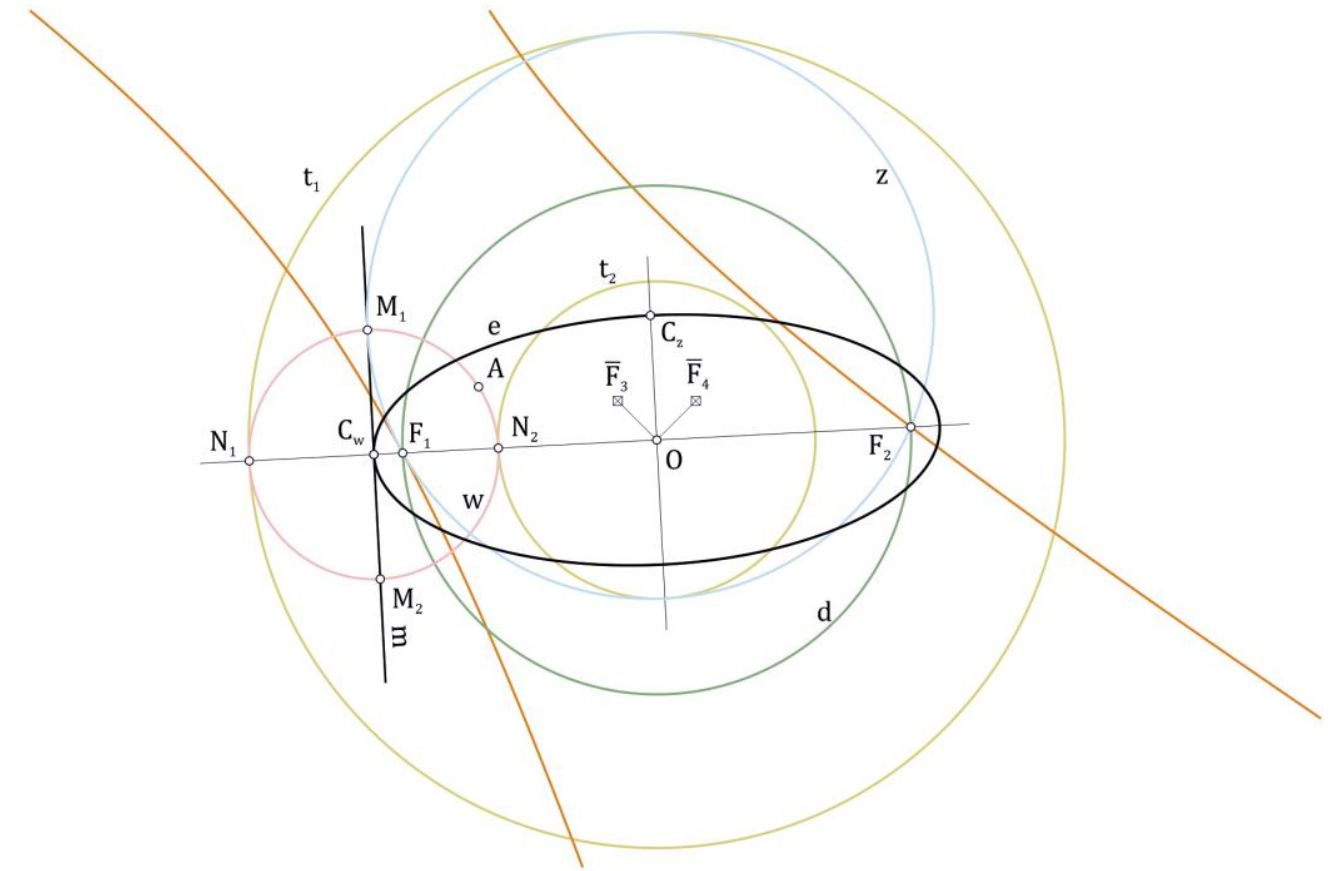

Figure 7: Elliptic curves induced by Laguerre points

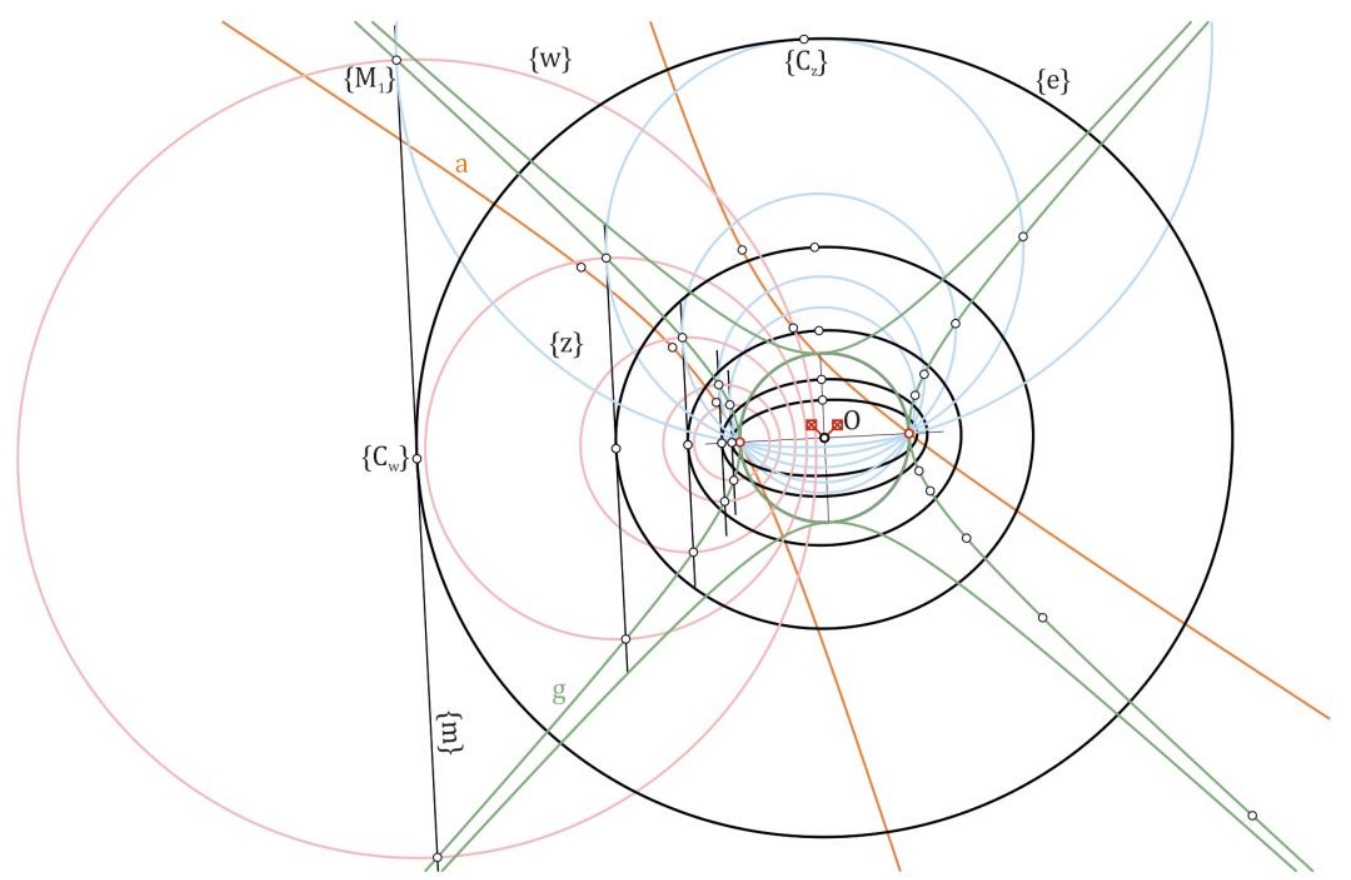

Figure 8: Set of curves induced by Laguerre points

\section{Conclusion}

As a result of the study, the following results were obtained:

- the properties of imaginary Laguerre points in their application to the problem of transforming two arbitrary non-degenerate conics into two circles have been studied;

- $\quad$ structural geometric schemes for solving the corresponding problems are presented; 
- the proof of the fact, that the radical axis is a circle of a special kind, split into a pair of straight lines; one of them is the infinitely distant straight line of the plane is given;

- a new constructive algorithm for the formation of a series of curved lines induced by Laguerre points is presented.

\section{References}

[1] I. Ya. Bakelman, Inversija, Nauka Publ., Moscow, 1966. (In Russian)

[2] E.V. Bindyukova, Tochki Lagerra v central'nom proecirovanii, Cand.Sc. thesis, Moscow, 1986. (In Russian)

[3] V. YA. Volkov, Kurs nachertatel'noj geometrii na osnove geometricheskogo modelirovaniya, SibADI Publ., Omsk, 2010. (In Russian)

[4] D.V. Voloshinov, Konstruktivnoe geometricheskoe modelirovanie. Teorija, praktika, avtomatizacija, Saarbrücken: Lambert Academic Publ., 2010. (In Russian)

[5] D. V. Voloshinov, Unified constructive algorithm for constructing foci of curves of the second order, Geometriya i grafika (2018) 47-54. doi: 10.12737/article_5b559dc3551f95.26045830. (In Russian)

[6] D. V. Voloshinov, Constructive geometric model of four-dimensional space as a basis for solving problems of zoning and positioning in the design of mobile networks, Trudy uchebnyh zavedenij svyazi (2018) 44-60. (In Russian)

[7] D. V. Voloshinov, On the refinement of some concepts of constructive geometry, in: Trudy Mezhdunarodnoj konferencii po komp'yuternoj grafiki i zreniyu "Grafikon", Tomsk, 2018, pp. 350-353. (In Russian)

[8] D.V. Voloshinov, K.N. Solomonov, Hardware and software implementation of constructive geometric models, in: Trudy Mezhdunarodnoj konferencii po komp'yuternoj grafiki i zreniyu "Grafikon", St. Peterburg, 2020, pp. 83-98. doi: 10.51130/graphicon-2020-1-83-98. (In Russian)

[9] D.V. Voloshinov, T.H. Zhuraeb, Development of a dynamic model of the blade working surface in the Simplex system, in: Sbornik nauchnyh trudov po materialam mezhdunarodnoj nauchnoprakticheskoj konferencii, St. Petersburg - Pushkin, 2020, pp. 292-295. (In Russian)

[10] A.G. Hirsch, V.A. Korotkij, Graphic Algorithms for Reconstructing a Second Order Curve Given by Imaginary Elements, Geometriya i grafika (2016) 19-30. doi: 10.12737/22840 (In Russian)

[11] A.G. Hirsh, Nagljadnaja mnimaja geometrija, Maska Publ., Moskow, 2008. (In Russian)

[12] A.G. Hirsch, New Descriptive Geometry Problems, Geometriya i grafika (2019) 18-33. doi: 10.12737/2308-4898-2020-18-33. (In Russian)

[13] N.A. Glagolev, Proektivnaja geometrija, Vysshaya shkola Publ., Moscow, 1963. (In Russian)

[14] O.A. Grafskij, Vvedenie mnimyh elementov v nachertatel'nuyu geometriyu, GOU VPO "Dalnevost. State universi-ty of communication lines. Ministry of Railways of Russia" Publ., Khabarovsk, 2004. (In Russian)

[15] I.D. Zhizhilkin, Inversija. MTSNMO Publ., Moscow, 2009. (In Russian)

[16] G.S. Ivanov, Konstruirovanie tekhnicheskih poverhnostej, Mashinostroenie Publ., Moskow, 1987. (In Russian)

[17] G.S. Ivanov, I.M. Dmitrieva, On descriptive geometry problems with imaginary solutions, Geometriya i grafika (2015) 3-8. (In Russian)

[18] V.A. Korotkij, Central projection of two coplanar conics in two circles, in: Materialy IV mezhdunarodnoj Internet-konferencii "Problemy kachestva graficheskoj podgotovki", Perm, 2014. (In Russian)

[19] V.A. Korotkij, Computer visualization of a second-order curve passing through imaginary points and touching imaginary lines, Nauchnaya vizualizaciya (2018) 56-68. (In Russian)

[20] V.A. Korotkij, Conical sections in computer graphics, in: Materialy 70-j nauchnoj konferencii Nauka YUUrGU, Yuzhnoural'sk, 2018, pp. 105-109. (In Russian)

[21] V.A. Korotkij, Imaginary linear elements in algebra, geometry and computer graphics, Prikladnaya matematika i fundamental'naya informatika (2019) 34-48. (In Russian)

[22] V.A. Korotkij, Contact of conical sections, Geometriya i grafika (2016) 36-45. doi: 10.12737/21532 (In Russian) 
[23] V.A. Peklich, Mnimaya nachertatel'naya geometriya, Association of construction universities Publ., Moscow, 2007. (In Russian)

[24] P.V. Filippov, Nachertatel'naja geometrija mnogomernogo prostranstva i ee prilozhenija, LENAND Publ., Moscow, 2016. (In Russian)

[25] N.F. Chetverukhin, Proektivnaja geometrija, Prosveshenie Publ., Moskow, 1953. (In Russian) 